\title{
Estudo químico de duas plantas medicinais da amazônia: Philodendron scabrum k. Krause (araceae) e Vatairea guianensis aubl. (fabaceae)
}

Ivonei OTTOBELLI ${ }^{1}$, Valdir Alves FACUNDO ${ }^{2}$, Juliana ZULIANI ${ }^{3}$, Cleber Calado LUZ ${ }^{4}$, Henrique Otávio Braga BRASIL ${ }^{5}$, Júlio Sanches Linhares Teixeira MILITÃO ${ }^{6}$, Raimundo BRAZ-FILHO

\section{RESUMO}

Este trabalho relata o estudo químico de duas plantas medicinais da Amazônia: Philodendron scabrum K. krause (Araceae) e Vatairea guianensis Aubl. (Fabaceae). As composiçóes dos óleos essenciais dos cipós de P. scabrum e dos frutos de V. guianensis, respectivamente, foram analisadas em CG-DIC e CG-EM. Os constituintes majoritários dos cipós de $P$. scabrum foram óxido de cariofileno (19,42\%), $\alpha$-copaeno $(16,08 \%)$ e $\beta$-bisaboleno (10,01\%); e nos frutos de $V$. guianensis foram o ácido (9Z)-octadecenoico $(24,95 \%)$ e o ácido docosahexaenoico (24,17\%). $\beta$-sitosterol e o alquilresorcinol 1-hexadecanoil-2,6dihidroxibenzeno foram isolados do extrato etanólico dos cipós de P. scabrum; e do extrato etanólico dos frutos de V. guianensis, foram isoladas as antraquinonas crisofanol e fisciona. As determinaçôes estruturais foram baseadas em dados de RMN de ${ }^{1} \mathrm{H}$ $\mathrm{e}^{13} \mathrm{C}$. RMN, uni e bidimensional e comparação com dados da literatura.

PALAVRAS-CHAVE: Philodendron scabrum, Vatairea guianensis, óleo essencial, antraquinonas

\section{Chemical study of two Amazonian medicinal plants: Philodendron scabrum K. Krause (Araceae) and Vatairea guianensis Aubl. (Fabaceae)}

\begin{abstract}
This work describes the chemical study of two medicinal plants of the Amazon Philodendron scabrum K. Krause (Araceae) and Vatairea guianensis Aubl. (Fabaceae). Essential oils composition from stems of Philodendron scabrum K. Krause (Araceae) and fruits of Vatairea guianensis Aubl. (Fabaceae), respectively were analyzed in GC-FID and GC-MS. The major constituents from stems of P. scarabum were caryophyllene oxide $(22.42 \%), \alpha$-copaene $(16.08 \%)$ and $\beta$-bisabolene $(12.01 \%)$ and from fruits of $V$. guianensis were (9Z)-octadecenoic acid (24.95\%) and docosahexenoic acid (24.17\%). $\beta$-sitosterol and alkylresorcinol 1-hexadecanoyl-2,6-dihydroxybenzene were isolated from ethanolic extracts from stems of $P$. scabrum and from ethanolic extracts from fruits of $V$. guianensis, the athraquinones chrysophanol and physcion were isolated. The structure of isolated compounds we determinate wered based on data from ${ }^{1} \mathrm{H}$ and ${ }^{13} \mathrm{C}$ NMR, including two dimensional analyses and comparison with literature data.
\end{abstract}

KEYWORDS: Philodendron scabrum, Vatairea guianensis, essential oil, anthraquinones

\footnotetext{
1 Instituto João Neórico. ivoneiottobelli@bol.com.br

2 Universidade Federal de Rondônia. vfacundo@unir.br

3 Instituto de Pesquisas Patológicas da Amazonia. zuliani.juliana@gmail.com

4 Instituto João Neórico. clebercalado@ymail.com

5 Instituto João Neórico. otaviohenryque@bol.com.br

6 Universidade Federal de Rondônia. militao@unir.br

7 Pesquisador visitante emérito-FAPERJ-UENF-UFRRJ. braz@uenf.br
} 


\section{INTRODUÇÃO}

A medicina tradicional baseia-se principalmente nas plantas medicinais. A utilizaçáo destas plantas, no tratamento e cura de algum tipo de doença, é uma prática milenar e, ainda hoje, aparece como o principal recurso terapêutico de muitos grupos e comunidades étnicas. As informaçôes populares conduziram, ao longo dos anos, uma gama de informações de grande validade com relação à eficiência e os efeitos medicinais das plantas. Estas informaçōes continuam sendo, até hoje, de grande importância e com isto mais estudos químicos com as plantas medicinais fazem-se necessários para validar o uso popular destes vegetais e identificar substâncias naturais bioativas.

A família Araceae compreende cerca de 105 gêneros e, aproximadamente, 3.300 espécies entre herbáceas e trepadeiras (Grayum 1990). Dentre os gêneros com maior número de espécies destacam-se Anthurium e Philodendron, com muitos representantes nativos do Brasil. Philodendron scabrum K. Krause (Araceae) é conhecida popularmente como "cipó ambé" e "banana ambé". O cipó é utilizado, principalmente, pela populaçáo do baixo Madeira, Porto Velho e Rondônia, no tratamento de mordida de serpente e a infusáo dos talos é utilizada como analgésico. $\mathrm{O}$ contato prolongado com as folhas de P. scabrum ocasiona irritação na pele. Existem registros na literatura relatando que espécies do gênero Philodendron apresentam constituintes químicos possuidores de atividade bactericida, antiprotozoárias contra Trypanossoma cruzi e Trichomonas vaginalis (Yoshikaqa et al. 1992; MuelasSerrano et al. 2000). Compostos alquil e arilresorcinol têm sido isolados de espécies deste gênero e caracterizados de acordo com seu grau de insaturação na cadeia alifática. Estes compostos são os responsáveis pelas atividades causadoras de dermatite alérgica ocasionada por plantas deste gênero (Ponchet et al. 1980; Knight et al. 1996).

A família Fabaceae, tem distribuição cosmopolita, apresentando entre 400 e 500 gêneros e mais de 10.000 espécies. Esta família é constituída por vegetais que fornecem os mais diversos produtos para a vida humana, como alimentos, forragem para a criação de gado, substâncias medicinais, pesticidas, combustíveis e produtos industriais (Harborne et al. 1971; Schwantes et al. 1981).

O gênero Vatairea, pertencente à família Fabaceae, compreende somente 7 espécies de árvores, as quais são difundidas no Brasil, na Guiana e nas regiôes litorais atlânticas da América Central e do México (Schongart et al. 2007). A espécie $V$. guianensis é uma árvore encontrada na regiāo Amazônica tanto em áreas inundadas como em áreas nãoinundadas (Parolin et al. 1998). O período de inflorescência ocorre nos meses de fevereiro e março e sua frutificação entre abril e junho (Schongart et al. 2002). A madeira é usada e comercializada principalmente na construção de casas
(Loureiro et al. 2000). É conhecida popularmente pelos nomes "fava-de-impigem", "fava-de-bolacha", "faveira-amarela", "faveira-de-impigem", "faveira grande" e "lombrigueira". Informaçôes populares reportam que a população da região do médio e baixo Amazonas utiliza as favas de espécies do gênero Vaitarea, principalmente as de V. guianensis, contra diversos tipos de micoses superficiais sob a forma de tintura alcoólica ou por aplicação direta de suas "amenduas" maceradas. A literatura registra os trabalhos de Formiga et al. (1975) que relatam o isolamento de crisofanol, emodina, formonometina, 7-hidroxiflavona, sitosterol e estigmasterol, a partir do extrato benzênico do tronco da $V$. heteroptera.

Este trabalho relata o estudo químico de duas plantas medicinais da regiâo Amazônica, P. scabrum e V. guianensis, objetivando contribuir para o conhecimento químico de plantas dos gêneros Philodendron e Vatairea.

\section{MATERIAL E MÉTODOS}

\section{Procedimentos experimentais}

Os pontos de fusão foram determinados em aparelho Mettler Toledo, com placa aquecedora modelo FP82HT e central de processamento FP90, acoplado a um microscópio óptico monocular. As determinações foram realizadas a uma velocidade de aquecimento de $6{ }^{\circ} \mathrm{C}$ por min. e os valores obtidos não foram corrigidos.

Os espectros de absorção na regiấo do infravermelho (IV) foram obtidos em espectrômetro Perkin Elmer, modelo FT-IR Spectrum 1000, usando-se pastilhas de KBr.

Os espectros $1 \mathrm{D}$ e $2 \mathrm{D}$ de ressonância magnética nuclear (RMN) foram registrados em espectrômetro Brucker DRX$500\left({ }^{1} \mathrm{H}: 500 \mathrm{MHz} ;{ }^{13} \mathrm{C}: 125 \mathrm{MHz}\right.$ ), utilizando-se $\mathrm{CDCl}_{3}$ como solvente e como referência interna o sinal residual do solvente usado.

\section{Material vegetal}

As amostras de P. scabrum e V. guianensis foram coletadas na área do Parque Ecológico de Porto Velho, Rondônia, em 14 de fevereiro de 2007. A identificaçáa botânica das plantas foi realizada pelo Dr. José Ferreira Ramos do herbário do Instituto Nacional de Pesquisa da Amazônia (INPA), onde as exsicatas encontram-se depositadas sob os números 213530 para $P$. scabrum e 223304 para V. guianensis.

\section{Analise dos óleos essenciais}

\section{CG-EM}

A caracterização dos componentes do óleo essencial por CG-EM foram realizadas em espectrômetro de massas modelo HP-5971A, acoplado a um cromatógrafo gasoso, modelo HP-5890A, série II, equipado com coluna capilar de fenilmetilsiloxano DB-5 (J e W) L = $30 \mathrm{~m}, \mathrm{di}=0,25 \mathrm{~mm}$, df 
$=0,25 \mu \mathrm{m}$, injetor tipo split-splitless, tendo hélio como gás de arraste (fluxo de $1,0 \mathrm{~mL}$ por min). Condiçôes cromatográficas: Injetor a $250{ }^{\circ} \mathrm{C}$ no modo split (1:6), detector a $280{ }^{\circ} \mathrm{C}$, temperatura inicial de $50^{\circ} \mathrm{C}$ seguido por uma rampa de 4 ${ }^{\circ} \mathrm{C}$ por min até $180^{\circ} \mathrm{C}$, e $20^{\circ} \mathrm{C}$ por min de $180{ }^{\circ} \mathrm{C}$ até 280 ${ }^{\circ} \mathrm{C}$. O modo de operaçáo do espectrômetro de massas foi por impacto de elétrons a $70 \mathrm{eV}$.

\section{CG-DIC}

As análises dos óleos essenciais por CG-DIC foram realizadas em um cromatógrafo CG17A (Shimadzu), equipado com DIC (detector de ionização por chama), injetor tipo splitsplitless. Coluna cromatográfica capilar de fenilmetilsiloxano DB-5 (J e W) L $=30 \mathrm{~m}, \mathrm{di}=0,25 \mathrm{~mm}, \mathrm{df}=0,25 \mu \mathrm{m}$, tendo hélio como gás de arraste (fluxo de $1,0 \mathrm{~mL}$ por min). Utilizou injetor a $280^{\circ} \mathrm{C}$ no modo split (1:5), detector a $280^{\circ} \mathrm{C}$ e temperaturas programadas: $35^{\circ} \mathrm{C}$ seguido de uma rampa de $5^{\circ} \mathrm{C}$ por min até $180^{\circ} \mathrm{C}$, depois $17^{\circ} \mathrm{C}$ por min até $280^{\circ} \mathrm{C}$ com uma isoterma de $10 \mathrm{~min}$.

Identificação dos constituintes químicos dos óleos essenciais

A identificação de cada constituinte foi realizada comparando-se o espectro de massas de cada componente com espectros de massas armazenados em espectroteca Wiley e banco de dados digital (Alencar et al. 1990), bem como por comparaçáo com espectros de massas disponíveis na literatura (Adams 1995) considerando rigorosamente o padrão de fragmentação, além do índice de Kovats corrigido para cada constituinte.

\section{Extrações dos óleos essenciais de $P$. scabrum e $V$. guianensis}

Os cipós frescos de P. scabrum $(2,5 \mathrm{Kg})$ e os frutos frescos de $V$. guianensis $(0,9 \mathrm{Kg})$, devidamente triturados, foram submetidos à hidrodestilação por 3 horas, utilizando-se extratores de vidro tipo Clevenger modificado. Os óleos essenciais extraídos foram secos com sulfato de sódio anidro, acondicionados em pequenos frascos de vidro âmbar e mantidos sob refrigeração antes de serem analisados.

\section{Isolamento dos constituintes fixos de $\boldsymbol{P}$. scabrum}

O material vegetal, $2,1 \mathrm{Kg}$ de cipó, após ter sido extraído o óleo essencial foi seco em estufa com ventilação a $60^{\circ} \mathrm{C}$, em seguida foi submetido à extração com etanol à temperatura ambiente por três dias ( $2 \times 3$ litros). A destilação do solvente sob pressão reduzida forneceu $46,0 \mathrm{~g}$ de extrato etanólico de coloraçáo marrom. Parte deste extrato $(32,0 \mathrm{~g})$ foi submetido a uma coluna filtrante de sílica gel, sendo eluído com hexano, acetato de etila e metanol. O eluato hexânico $(8,3$ g) foi submetido a uma cromatografia em coluna de sílica gel e eluído com hexano: acetato de etila em gradiente de polaridade crescente. Desta forma foram obtidas 34 fraçóes que, após comparação em cromatografia em camada delgada de sílica, foram reunidas, resultando em 12 fraçóes F-1-12. A fração F-5 (149,1 mg) foi submetida a uma cromatografia em coluna de sílica e eluída com hexano: acetato de etila em gradiente de polaridade crescente, levando desta forma ao isolamento do composto 1. A Fração F-10 foi submetida às mesmas condiçóes cromatográficas citadas acima que levaram ao isolamento do composto 2 .

\section{Isolamento dos constituintes fixos de $\boldsymbol{V}$. guianensis}

O material vegetal $0,7 \mathrm{Kg}$ de frutos, após ter sido extraído o óleo essencial, foi seco em estufa com ventilação a $60^{\circ} \mathrm{C}$, em seguida foi submetido à extraçáo com etanol a temperatura ambiente por três dias $(2 \times 1,5$ litros $)$. A destilação do solvente sob pressão reduzida forneceu $16,0 \mathrm{~g}$ de extrato etanólico de coloração marrom. Parte deste extrato $(14,2 \mathrm{~g})$ foi submetido a uma coluna filtrante de sílica gel, sendo eluído com hexano, clorofórmio, acetato de etila e metanol. O eluato clorofórmio $(8,3 \mathrm{~g})$ foi submetido a uma cromatografia em coluna de sílica e eluída com hexano: clorofórmio em gradiente de polaridade crescente. Desta forma foram obtidas 44 fraçôes que, após comparação em cromatografia em camada delgada de sílica, foram reunidas, resultando em 22 fraçōes F-1-22. A fração F-19 (240,1 mg) foi submetida a uma cromatografia em coluna de sílica e eluída com hexano: clorofórmio em gradiente de polaridade crescente, levando desta forma ao isolamento do composto 3. A fraçáo F-21 foi submetida as mesmas condiçóes cromatográficas citadas acima que levaram ao isolamento do composto 4 .

\section{RESULTADOS E DISCUSSÃO}

Neste trabalho foram obtidos os óleos essenciais dos cipós de P. scabrum e dos frutos de V. guianensis, respectivamente. Os rendimentos dos óleos essenciais, calculados sobre a massa do material fresco, foram de $0,05 \%$ para os cipós de $P$. scabrum e $0,12 \%$ para os frutos de V. guianensis. Os componentes químicos identificados em ambos os óleos, incluindo seus respectivos tempos de retenção, índices de Kovats e porcentagens, estão sumarizados na Tabela 1. Foram determinadas as composiçôes químicas dos óleos essenciais em um elevado percentual, 91,74\% para os cipós de P. scabrum e 90,23\% para os frutos de V. guianensis.

O óleo essencial dos cipós de $P$. scabrum revelou ser constituído por $9,63 \%$ de monoterpenos e $82,11 \%$ de sesquiterpenos. Os sesquiterpenos majoritários foram o óxido de cariofileno (19,42\%), $\alpha$-copaeno (16,08\%) e $\beta$-bisaboleno $(10,01 \%)$, enquanto o $\alpha$-zingibereno, $\alpha$-bergamoteno, $\alpha$-curcumeno e óxido de humuleno tiveram percentuais muito parecidos, em torno de 6,0\%. Com o objetivo de realizar uma possível comparação entre a composição química do óleo essencial de plantas do gênero Philodendron, foi realizada uma 
busca na literatura e somente dois estudos foram encontrados. No primeiro foram estudadas seis amostras de óleos essenciais das raízes de $P$. acutatum, coletadas no norte do Brasil (Viana et al. 2002). Os constituintes majoritários foram $\alpha$ e $\beta$-pineno com um percentual em torno de $23,0 \%$, as cetonas 2 -undecanona e 2 -tridecanona com um percentual variando entre 21,8 a $34,3 \%$ e o $\beta$-bisaboleno com concentração variando entre 0,8 e $49,5 \%$. O segundo registro trata da composição química do óleo essencial das raízes de $P$. imbé, sendo que os constituintes majoritários detectados foram o $\alpha$ e $\beta$-pineno $13,3 \%$ e $15,8 \%$, respectivamente, limoneno $15,5 \%$, espatulenol $14,2 \%$ e óxido de cariofileno $10,3 \%$ (Bezerra et al. 2002). Uma rápida comparaçâo revelou que no óleo essencial dos cipós de P. scabrum, os constituintes $\alpha$ e $\beta$-pineno, óxido de cariofileno, limoneno e $\beta$-bisaboleno, estão presentes em grande parte das amostras dos óleos estudados. Outra observaçáo é a grande concentraçáo de sesquiterpenos identificados no óleo essencial de P. scabrum (82,11\%) e um pequeno percentual nos óleos essenciais de $P$. acutatum e $P$. imbé, abaixo de 5\% (Viana et al. 2002; Bezerra et al. 2002).

$\mathrm{O}$ óleo essencial dos frutos de $V$. guianensis apresentou-se muito viscoso e com uma coloração vermelha. Sua constituição revelou ser, quase que exclusivamente, formada por aldeídos $(23,26 \%)$ e ácidos carboxílicos (64,73\%). Entre os aldeídos identificados, o dodecanal foi o que se apresentou em maior concentração 7,98\%. Dos ácidos carboxílicos identificados, $49,12 \%$ correspondem a dois ácidos graxos cis-insaturados, o ácido (9Z)-octadecenóico $(24,95 \%)$ e o ácido docosaexaenóico (24,17\%), sendo este último pertencente à classe dos ômegas-3 (Carvalho et al. 2003). O ácido graxo docosahexaenóico, também conhecido como o DHA (22:6n-3), tem importante função na formaçấo, desenvolvimento e funcionamento do cérebro e da retina (Chen et al. 1996; Sangiovanni e Chew 2005). O ácido graxo (9Z)-9-octadecenóico, também conhecido como oléico, é um ácido graxo essencial (Omega-9), o qual participa do nosso metabolismo, desempenhando um papel fundamental na síntese dos hormônios (Sangiovanni e Chew 2005).

O fracionamento do eluato hexânico empregando a cromatografia em gel de sílica, levou ao isolamento de dois compostos o esteróide 1 e o alquilresorcinol 2. Com base nas análises dos dados espectroscópicos de $\mathrm{RMN}{ }^{1} \mathrm{H} \mathrm{e}{ }^{13} \mathrm{C} \mathrm{e}$ comparação com dados na literatura, foi possível identificar o composto 1 , como sendo o esteróide $\beta$-sitosterol $(34,1 \mathrm{mg}$, Macari et al. 1990; p.f. $136{ }^{\circ}$ C, lit. Dela Greca et al. 1990 , $\left.137^{\circ} \mathrm{C}\right)$.

O espectro na regiáo do infravermelho do composto 2 exibiu bandas de absorção, entre outras, em $3385 \mathrm{~cm}^{-1}$ de ligação hidrogênio intramolecular, $1635 \mathrm{~cm}^{-1}$ de grupamento carbonila e absorçốes de átomos de hidrogênios aromáticos em 1604,1511 e $1455 \mathrm{~cm}^{-1}$. O espectro de massa exibiu um pico em m/z 348 u.m.a, compatível com uma formula molecular
Tabela 1 - Composição química (\%), Tempo de Retenção (TR) e Índice Kovats calculado (IKc) do cipó de P. scabrum e dos frutos de V. guianensis.

\begin{tabular}{|c|c|c|c|c|}
\hline \multirow{2}{*}{ Constituintes } & \multirow{2}{*}{ (TR) } & \multirow{2}{*}{$\left(\mathrm{IK}_{\mathrm{c}}\right)$} & \multirow{2}{*}{$\begin{array}{c}\text { P. Scabrum } \\
(\%)\end{array}$} & \multirow{2}{*}{$\begin{array}{c}\text { V. guianensis } \\
(\%)\end{array}$} \\
\hline & & & & \\
\hline hexanal & 3,3 & 789 & - & 4,39 \\
\hline (2Z)-heptenal & 7,5 & 890 & - & 1,87 \\
\hline$\alpha$-pineno & 6,7 & 937 & 3,90 & - \\
\hline$\beta$-pineno & 8,3 & 969 & 2,34 & - \\
\hline limoneno & 10,5 & 1013 & 3,39 & - \\
\hline$(3 E)$-octen-2-ol & 13,7 & 1042 & - & 0,79 \\
\hline$\alpha$-copaeno & 28,6 & 1375 & 16,08 & - \\
\hline nonanal & 14,7 & 1075 & - & 2,67 \\
\hline (2E)-decenal & 21,9 & 1261 & - & 2,03 \\
\hline dec-9-en-1-ol & 22,7 & 1263 & - & 1,45 \\
\hline ácido nonanóico & 23,6 & 1284 & - & 0,75 \\
\hline$(2 E, 4 E)$-decadienal & 25,7 & 1338 & - & 1,38 \\
\hline undecenal & 27,7 & 1380 & - & 2,94 \\
\hline$\alpha$-cedendro & 28,3 & 1381 & 0,98 & - \\
\hline dodecanal & 27,8 & 1388 & - & 7,98 \\
\hline$\beta$-elemeno & 29,4 & 1390 & 0,84 & - \\
\hline$\alpha$-zingibereno & 30,3 & 1410 & 6,10 & - \\
\hline$\gamma$-elemeno & 31,0 & 1435 & 0,91 & - \\
\hline$\alpha$-bergamoteno & 31,7 & 1436 & 6,01 & - \\
\hline$\gamma$-gurjuneno & 32,1 & 1475 & 0,77 & - \\
\hline$\alpha$-amorfeno & 33,7 & 1478 & 1,00 & - \\
\hline$\alpha$-curcumeno & 34,3 & 1487 & 6,40 & - \\
\hline$\beta$-selineno & 34,3 & 1491 & 1,01 & - \\
\hline biciclogermacreno & 35,1 & 1500 & 1.03 & \\
\hline$\beta$-bisaboleno & 35,6 & 1514 & 10,01 & - \\
\hline$\delta$-cadineno & 35,4 & 1521 & 0,31 & \\
\hline$\gamma$-muuroleno & 35,8 & 1523 & 1,91 & \\
\hline germacreno B & 36,2 & 1560 & 0,91 & \\
\hline óxido de cariofileno & 39,9 & 1584 & 19,42 & - \\
\hline óxido de humuleno & 40,7 & 1609 & 6,74 & - \\
\hline aristolona & 47,9 & 1747 & 1,68 & - \\
\hline ácido docosahexaenóico & 50,8 & 1949 & - & 24,17 \\
\hline ácido hexadecanóico & 51,8 & 1955 & - & 1,29 \\
\hline $\begin{array}{l}\text { ácido (9Z)-9- } \\
\text { octadecenóico }\end{array}$ & 52,5 & 1990 & - & 24,95 \\
\hline ácido esteárico & 52,7 & 1995 & - & 13,57 \\
\hline Monoterpenos & - & - & 9,63 & - \\
\hline Sesquiterpenos & - & - & 82,11 & - \\
\hline Aldeídos & - & - & - & 23,26 \\
\hline Ácidos carboxílicos & - & - & - & 64,73 \\
\hline Outros & - & - & - & 2,24 \\
\hline Total identificado & - & - & 91,74 & 90,23 \\
\hline
\end{tabular}

$\mathrm{C}_{22} \mathrm{H}_{36} \mathrm{O}_{3}$. O espectro de $\mathrm{RMN}{ }^{1} \mathrm{H}$ exibiu duas absorçôes em $\delta$ $7,21(\mathrm{t}, J=8,2 \mathrm{~Hz}, 1 \mathrm{H})$ e $6,36(\mathrm{~d}, J=8,2 \mathrm{~Hz}, 2 \mathrm{H})$, características de anel 1,2,3-tri-substituído, e uma absorção em $\delta$ 9,68 (sl) de hidroxila fenólica quelada por ligação de hidrogêniocarbonila. $\mathrm{O}$ espectro de $\mathrm{RMN}{ }^{13} \mathrm{C}$ confirmou a presença de um grupamento carbonila através da linha espectral em $\delta$ 
208,1. Através da análise do espectro de $\mathrm{RMN}{ }^{13} \mathrm{C}$ utilizando a técnica DEPT-135 foi possível observar-se que o composto 2 apresenta quatro átomos de carbonos não-hidrogenados, três metínicos, um metílico e quatorze carbonos metilênicos. $\mathrm{O}$ espectro bidimensional de correlação heteronuclear ${ }^{13} \mathrm{C}$ ${ }^{1} \mathrm{H}$ (HMQC) confirmou o padrão de substituição do anel aromático através das correlaçôes em $\delta_{\mathrm{C}-\mathrm{H}} 135,7-7,21(\mathrm{t}, J=8,2$ $\mathrm{Hz}, 1 \mathrm{H})$ e 108,1 - 6,36 (d, J=8,2 Hz, 2H). Com a observação nos espectros de $\mathrm{RMN}{ }^{1} \mathrm{He} \mathrm{e}^{13} \mathrm{C}$ em $\delta_{\mathrm{H}} 3,11$ (t, $J=13,3$ e 7,0 $\mathrm{Hz}, 3 \mathrm{H})$ e em $\delta_{\mathrm{C}} 14,2$, respectivamente, de um grupamento metila, confirmado através do espectro bidimensional HMQC, e um pico no espectro de massa em m/z 152 u.m.a., resultante de um rearranjo de McLafferty, foi possível propor que o composto 2 tem uma estrutura semelhante a do 1-hexadecanoil-2,6-dihidroxibenzeno (Kato et al. 1985). Os dados completos de $\mathrm{RMN}{ }^{1} \mathrm{H} \mathrm{e} \mathrm{e}^{13} \mathrm{C}$ do composto 2 estáo relacionados na Tabela 2 .
Do extrato etanólico dos frutos de $V$. guianensis foram isolados dois sólidos amarelos os quais foram identificadas como sendo duas antraquinonas: crisofanol 3 e fisciona 4 . As estruturas das antraquinonas 3 e 4 foram elucidadas através da análise dos espectros de $\mathrm{RMN}{ }^{1} \mathrm{H}$ e ${ }^{13} \mathrm{C}$ e comparação com dados na literatura, (Meselhy 2003; Barbosa et al. 2004). O espectro de RMN ${ }^{1} \mathrm{H}$ revelou para cada antraquinona dois sinais simples $\left[\delta_{\mathrm{H}} 12,02\right.$ e 12,12 (3); 12,11 e 12,32 (4)] referentes aos grupamentos hidroxilas queladas por ligaçáo hidrogênio-carbonila e em $\delta_{\mathrm{H}} 2,43$ (s) (3) e 2,46 (s) (4), um sinal integrado para três hidrogênios referente aos grupamentos metila. O espectro de $\mathrm{RMN}{ }^{1} \mathrm{H}$ de 3 apresentou sinais em $\delta_{\mathrm{H}}$ $7,79$ (dd, $J=1,7 ; 7,93 \mathrm{~Hz} ; 1 \mathrm{H})$ e $7,56(\mathrm{dd}, J=1,5 ; 7,93 \mathrm{~Hz}$; $1 \mathrm{H})$, característico de hidrogênios com acoplamento orto e meta. $\operatorname{Em} \delta_{\mathrm{H}} 7,23(\mathrm{~d}, J=1,4 \mathrm{~Hz} ; 1 \mathrm{H})$ e $7,37(\mathrm{~d}, J=1,4 \mathrm{~Hz}$; $1 \mathrm{H})$ de dois hidrogênios acoplando em posiçóes meta e um

Tabela 2 - Dados de RMN ${ }^{1} \mathrm{H}(400 \mathrm{MHz})$ e ${ }^{13} \mathrm{C}$ (100 MHz) para os compostos 2-4 (CDCl ${ }_{3}$ ) como solvente. Deslocamento químico $(\delta$, ppm), multiciplidade e constante de acoplamento $(\mathrm{J}, \mathrm{Hz}$, entre parêntese)

\begin{tabular}{|c|c|c|c|c|c|c|}
\hline \multirow{2}{*}{ C } & \multicolumn{2}{|r|}{2} & \multicolumn{2}{|r|}{3} & \multicolumn{2}{|c|}{4} \\
\hline & $\delta_{c}$ & $\delta_{H}$ & $\delta_{c}$ & $\delta_{\mathrm{H}}$ & $\delta_{c}$ & $\delta_{\mathrm{H}}$ \\
\hline 1 & 110,0 & - & 162,7 & - & 161,3 & - \\
\hline $2 / 6$ & 161,2 & & 124,4 & $7,23, d,(1,4)$ & 124,0 & $7,21, \mathrm{~d},(1,4)$ \\
\hline $3 / 5$ & 108,1 & $6,36, d,(8,2)$ & 149,3 & - & 149,1 & - \\
\hline 4 & 135,7 & $7,21, t,(8,2)$ & 121,4 & $7,37, d,(1,4)$ & 120,4 & $7,53, d,(1,4)$ \\
\hline 5 & - & - & 119,9 & $7,79, \mathrm{dd},(1,70 ; 7,93)$ & 109,8 & $7,20, d,(2,0)$ \\
\hline 6 & - & - & 136,9 & $7,70, \mathrm{~m}$ & 166,1 & \\
\hline 7 & 208,1 & - & 124,5 & $7,56, \mathrm{dd},(1,5 ; 7,93)$ & 107,6 & $6,89, \mathrm{~d},(2,0)$ \\
\hline 8 & 44,8 & $3,13, t,(14,8 ; 7,5)$ & 162,4 & - & 164,4 & - \\
\hline 9 & 31,9 & $1,70, \mathrm{~m}$ & 192,5 & - & 191,6 & - \\
\hline 10 & 29,3 & - & 181,9 & - & 181,2 & - \\
\hline 11 & 29,3 & - & 133,6 & - & 133,3 & - \\
\hline 12 & 29,3 & - & 115,9 & - & 115,8 & - \\
\hline 13 & 29,3 & - & 113,7 & - & 113,9 & - \\
\hline 14 & 29,3 & - & 133,3 & - & 132,8 & - \\
\hline 15 & 29,3 & - & 21,6 & $2,43, s$ & 21,6 & $2,46, s$ \\
\hline 16 & 29,3 & - & - & - & - & - \\
\hline 17 & 29,3 & - & - & - & - & - \\
\hline 18 & 29,3 & - & - & - & - & - \\
\hline 19 & 29,3 & - & - & - & - & - \\
\hline 20 & 24,4 & - & - & - & - & - \\
\hline 21 & 22,7 & - & - & - & - & - \\
\hline 22 & 14,2 & $3,11, \mathrm{t},(13,3 ; 7,0)$ & - & - & - & - \\
\hline $\mathrm{HO}-2 / 6$ & - & $9,68, \mathrm{sl}$ & - & - & - & - \\
\hline $\mathrm{HO}-8$ & - & - & - & $12,02, \mathrm{sl}$ & - & $12,11, \mathrm{sl}$ \\
\hline $\mathrm{HO}-1$ & - & - & - & $12,12, \mathrm{sl}$ & - & $12,32, \mathrm{sl}$ \\
\hline $\mathrm{OCH}_{3}$ & - & - & - & - & 56,3 & $3,92, \mathrm{~s}$ \\
\hline
\end{tabular}


multipleto em $\delta_{\mathrm{H}} 7,70(1 \mathrm{H})$. O espectro de $\mathrm{RMN}{ }^{1} \mathrm{H}$ de 4 mostrou quatro sinais em $\delta_{\mathrm{H}} 7,21(\mathrm{~d}, J=1,4 \mathrm{~Hz} ; 1 \mathrm{H}), 7,53(\mathrm{~d}$, $J=1,4 \mathrm{~Hz} ; 1 \mathrm{H}), 7,20$ (d, J=2,0 Hz; 1H) e $6,89(\mathrm{~d}, J=2,0 \mathrm{~Hz} ; 1 \mathrm{H})$, característicos de hidrogênios acoplando em posiçôes meta. A antraquinona 4 apresentou também um sinal referente aos $3 \mathrm{H}$ de uma metoxila em $\delta_{\mathrm{H}} 3,92(\mathrm{~s})$. Essas informaçóes juntamente com a análise dos espectros de $\mathrm{RMN}{ }^{13} \mathrm{C}$ e comparação com valores da literatura permitiram determinar as estruturas de 3 e 4 como sendo, 1,8-diidroxi-3-metilantraquinona (crisofanol 3, 34,1 mg, p.f. $194^{\circ} \mathrm{C}$, lit. Meselhy 2003; Barbosa et al. 2004, $198{ }^{\circ} \mathrm{C}$ ) e 1,8-diidroxi-3-metil-6-metoxiantraquinona (fisciona 4, 29,3 mg, p.f. $206{ }^{\circ} \mathrm{C}$, lit. Meselhy 2003; Barbosa et al. 2004, $210{ }^{\circ} \mathrm{C}$ ). Os dados completos de RMN ${ }^{1} \mathrm{H} \mathrm{e}{ }^{13} \mathrm{C}$ dos compostos 3 e 4 estão relacionados na Tabela 2. Esta é a primeira vez que está sendo divulgada a composição química dos óleos essenciais do cipó de P. scabrum e dos frutos de $V$. guianensis. $\mathrm{O}$ alquilresorcinol 2 já foi isolado dos frutos de Virola elongata (Kato et al. 1985), porém está é a primeira vez que foi isolado de P. scabrum. É também, a primeira vez que estão sendo divulgados os dados de $\mathrm{RMN}{ }^{13} \mathrm{C}$ desta substância. Não existem registros na literatura atribuindo atividade biológica para o 1-hexadecanoil-2,6-dihidroxibenzeno 2.

No decorrer dos anos, é crescente o interesse farmacológico pelos alquilresorcinois devido as várias atividades biológicas apresentadas por estas substâncias (Kozubek e Tyman 1999). Esta classe de compostos é muito comum em plantas da família Anacardiaceae com atividades antimicrobiana, antiviral, antifúngica, anticâncer, cardiovascular, anti-inflamátoria, antioxidante, nematocida, e outras têm sido atribuídas a vários alquilresorcinol isolados de espécies desta família (Jin e Zjawiony 2006; Kozubek e Tyman 1999; 2005).

Formiga et al. (1975), relatam o isolamento do crisofanol 3 no extrato benzênico do tronco de $V$. heteroptera e especulam a ocorrência desta antraquinona no extrato benzênico do tronco de $V$. guianensis e $V$. macrocarpa. Com isto, conclui-se que esta é primeira vez que estas duas antraquinonas, crisofanol 3 e fisciona 4 foram isoladas e identificadas nos frutos de $V$ guianensis. Registros na literatura relatam atividades antifúngica, anticancerígenas e bactericida para o crisofanol 3 e fisciona 4 (Zhou et al. 2006; Coopoosamy e Magwa 2006; García-Rosa et al. 2006; MinKyun et al. 2008).

De acordo com o presente estudo químico do cipó de $P$. scabrum, foi possível isolar e identificar o composto alquilresorcinol 1-hexadecanoil-2,6-dihidroxibenzeno, estudos biológicos com este composto fazem-se necessários para conhecer a cito toxidade bem como as suas possíveis aplicaçóes farmacológicas. As informaçôes populares sobre a V. guianensis relata seu uso no tratamento de micoses superficiais, como por exemplo, impingem, o que pode ser explicado pela presença das antraquinonas isoladas crisofanol 3 e fisciona 4, possuídoras de atividades antifúngica (Kozubek e Tyman 1999; 2005).

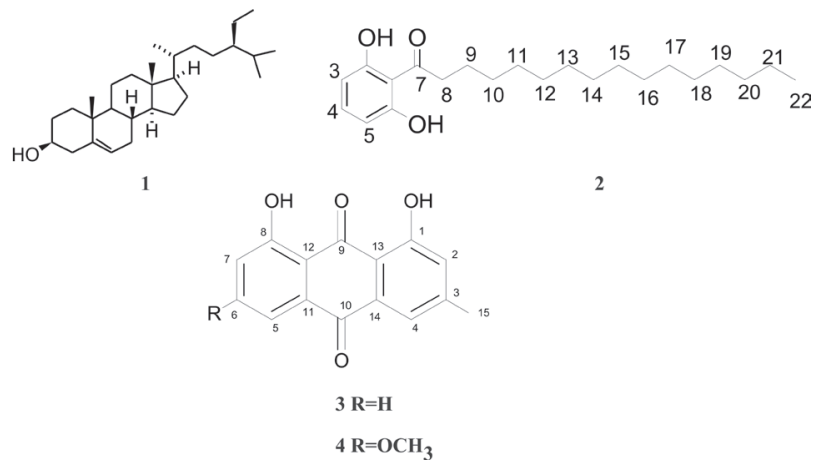

Figura 1 - Estruturas químicas das substâncias isoladas de $P$. scabrum $1 \mathrm{e}$ 2 e $V$. guianensis 3 e 4.

\section{AGRADECIMENTOS}

Ao CNPq, pelas bolsas e auxílios financeiros concedidos, ao Centro Nordestino de Aplicação e Uso de Ressonância Magnética Nuclear (CENAUREMN) - Programa de PósGraduação em Química Orgânica, Programa de Mestrado e Doutorado em Biologia Experimental da Fundação Universidade Federal de Rondônia, Departamento de Química Orgânica e Inorgânica, Centro de Ciências, UFC pelos espectros 1D e 2D de Ressonância Magnética Nuclear (RMN ${ }^{1} \mathrm{H}$ e $\mathrm{RMN}{ }^{13} \mathrm{C}$ ) e ao Dr. José Ferreira Ramos do herbário do Instituto Nacional de Pesquisa da Amazônia (INPA).

\section{BIBLIOGRAFIA CITADA}

Adams, R.P. 1995. Identification of essential oil components by gas chromatography/mass spectrometry. Allured Publ Corp., Carol Stream, IL. 469 pp.

Alencar, J.W.; Craveiro, A.A.; Matos, F.J.A.; Machado, M.I.L. 1990. Kovats Indices Simulation in Essential Oil Analysis. Quimica Nova, 13: 282-284.

Barbosa, F.G.; Oliveira, M.C. F.; Braz-Filho, R.; Silveira, E.R. 2004. Anthraquinones and naphthopyrones from Senna rugos. Biochemical Systematics and Ecology, 32: 363-365.

Bezerra, M.Z.B.; Andrade-Neto, M.; Freitas, R.M.; Feitosa C.M. 2002. The root oil of Philodendron imbe Schott (Araceae). Journal Essential Oil Research, 14: 56-57.

Carvalho, P.O.; Campos, P.R.B.; Noffs, M.A.; Oliveira, J.G.; Shimizu, M.T.; Da Silva, D.M. 2003. Application of microbial lipases to concentrate polyunsaturated fatty acids. Quimica Nova, 26: 75-80. (in Portuguese, with abstract in English)

Chen, Y.; Hougton, L.A.; Brenna, J.T.; Noy, N. 1996. Docosahexaenoic Acid Modulates the Interactions of the Interphotoreceptor Retinoid-binding Protein with 11-cisRetinal. The Journal of Biological Chemistry, 271: 20507-20515.

Coopoosamy, R.M.; Magwa, M.L. 2006. Antibacterial activity of chrysophanol isolated from Aloe excelsa (Berger). African Journal of Biotechnology, 5: 1508-1510. 
Formiga, M.D.; Gottlieb, O.R. ; Mendes, P.H.; Koketsu, M.; Almeita, M. E.; Pereira, M. O. S.; Magalhães, M.T. 1975. Constituints of Brazilian Leguminosae. Phytochemistry, 14: 828-830.

García-Rosa, K.; Villarreal-Alvarez, N.; Lübben, P.; Peña-Rodríguez, L.M. 2006. Chrysophanol, an Antimicrobial Anthraquinone from the Root Extract of Colubrina greggii. Journal Mexican Chemistry Society, 50: 76-78.

Grayum, M.H. 1990. Evolution and Phylogeny of the Araceae. Annals of the Missouri Botanical Garden, 77: 628-697.

Harborne, J.B.; Boulterm, P.; Turner, L. 1971. Chemotaxonomy of the Leguminosae. London, Academic Press.

Kato, M.J.; Lopes, L.M. X.; Paulino, F.H.F.; Yoshida, M.; Gottlieb, O.R. 1985. Acylresorcinol from Virola sebifere and Virola elongata. Phytochemistry, 24: 533-535.

Jin, W.; Zjawiony, J.K. 2006. 5-Alkylresorcinols from Merulius incarnatus. Journal Natural Product, 69: 704-706.

Knight, T.E.; Boll, P.; Epstein, W.L.; Prasad, A.K. 1996. Resorcinols and Catechols: A Clinical Study of Cross-sensitivity. American Journalof Contact Dermatitis, 7: 138-145.

Kozubek, A.; Tyman, J.H.P. 1999. Resorcinolic lipids, the natural nonisoprenoid phenolic amphiphiles and their biological activity. Chemical Reviews, 99: 1-25.

Kozubek, A.; Tyman, J.H.P. 2005. Bioactive phenolic lipids. Studies in Natural Products Chemistry, 30: 111-190.

Loureiro, A.A.; Freitas, J.A.; Ramos, K.B.L.; Freitas, C.A.A. 2000. Lumber Essences of the Amazon. Vol. 4: Ministério da Ciência e Tecnologia/Instituto Nacional de Pesquisas da Amazonia-CPPF, Manaus. 103 pp. (in Portuguese)

Macari, P.A.T.; Emerenciano, V.P.; Ferreira, Z.M.G.S. 1990. Identification of triterpenes from Miconia albicanstriana through analysis by microcomputer. Quimica Nova, 13: 260-262. (in Portuguese, with abstract in English).

Meselhy, M.R. 2003. Constituents from Moghat, the Roots of Glossostemon bruguieri (Desf.). Molecules, 8: 614-621.

MinKyun, N.; Jin, W.Y.; Min, B.S.; Ahn, J.S.; Bae, K. 2008. Protein Tyrosine Phosphatase 1B inhibitory Activity of Anthraquinones and Stilbenes. Natural Product Sciences, 14: 143-146.
Parolin, P.; Ferreira, L.V. 1998. Are there differences in specific wood gravities between trees in várzea and igapó (Central Amazonia). Ecotropica, 4: 25-32.

Ponchet, M.; Martin-Tanguy, J.; Marais, A.; Martin, C. 1980. Hydroxycinnamoyl acid amides and aromatic amines in the inflorescences of some Araceae species. Phytochemistry, 21: 2865-2869.

Sangiovanni, J. P; Chew, E.Y. 2005. The role of omega-3 long-chain polyunsaturated fatty acids in health and disease of the retina. Retinal and Eye Research, 24: 87-138.

Schöngart, J.; Piedade, M.T.F.; Ludwigshausen, S.; Horna, V.; Worbes, M. 2002. Phenology and stem-growth periodicity of tree species in Amazonian floodplain forests. Journal of Tropical Ecology, 18: 581-597.

Schongart, J.; Junk, W.J.J. 2007. Forecasting the flood-pulse in Central Amazonia by ENSO-indices. Journal Hydrology, 335: 124-132.

Schwantes, H.O.; Weberling, F. 1981. Plant taxonomy. São Paulo, Ed. Pedagógica e Universitária Ltda. 72 pp. (in Portuguese)

Muelas-Serrano, S.; Nogal, J.J.; Martínez-Díaz, R.A.; Escario, J.A.; Martínez-Fernández, A.R.; Gómez-Barrio, A. 2000. In vitro screening of American plant extracts on Trypanosoma cruzi and Trichomonas vaginalis. Journal of Ethnopharmacology, 71: 101-107.

Viana F; Andrade-Neto, M.; Pouliquen, Y.B.; Lucie, V.G. 2002. Chemical Composition of the Essential Oil from Roots of Philodendron acutatum Schott. Journal Essential Oil Research, 14:172-174.

Yoshikaqa, K.; Kishi, K.; Arihara, S. 1992. Limonoids and protolimonoids from the frits of Phyllodendron amurense. Phytochemistry, 31: 1335-1338.

Zhou, X.; Song, B.; Jin, L.; Hu, D.; Diao, C.; Xu, G.; Zou, Z.; Yang, S. 2006. Isolation and inhibitory activity against ERK Phosphorylation of hydroxyanthraquinones from rhubarb. Bioorganic e Medicinal Chemistry Letters, 16: 563-568.

Recebido em 17/05/2010

Aceito em 18/09/2010 